$\underline{1 \text { Pınar Haznedar, }}{ }^{2}$ Özlem Doğan, ${ }^{3}$ Pelin Albayrak, ${ }^{3}$ Gökçen Öz Tunçer, ${ }^{3}$ Serap Teber, ${ }^{3}$ Gülhis Deda, ${ }^{4} \mathrm{~F}$. Tuba Eminoğlu
1. Ankara University Faculty Of Medicine, Department Of Pediatrics, Ankara - Turkey
2. Ankara University Faculty Of Medicine, Department Of Biochemistry, Ankara - Turkey
3. Ankara University Faculty Of Medicine, Department Of Pediatrics, Division Pediatric Neurology, Ankara - Turkey
4. Ankara University Faculty Of Medicine, Department Of Pediatrics, Division Pediatric Metabolism, Ankara - Turkey

Background and Aims: We investigated oxidative stress parameters, carnitine levels, liver function tests (LFT) and their relationship in epileptic children treated with valproic acid or levetiracetam to have a better understanding on AED usage and OD.

Method: LFTs, serum free carnitine and oxidative damage markers and their relations with each other were determined in patients who are on valproic acid or levetiracetam treatment at least for 6 months. 25 patients on therapeutic doses of valproic acid, 26 patients on therapeutic doses of levetiracetam and 26 healthy volunteers as controls were included. LFTs, ammonia, carnitine, lipid peroxidation biomarker malondialdehyde (MDA) and a sensitive marker of DNA damage, 8-hydroxy-2-deoxyguanosine (8-OHdG) levels were measured.

\begin{tabular}{|c|c|}
\hline Inclusion Criteria & Exclusion Criteria \\
\hline $\begin{array}{l}\text { - }>2 \text { years of age } \\
\text { - Diagnosed with generalized epileptic seizures (ILAE) } \\
\text { Therapeutic doses of VPA (20-60mg/kg/day) and LEV (20- } \\
60 \mathrm{mg} / \mathrm{kg} / \mathrm{day}) \text { at least for } 6 \text { months }\end{array}$ & $\begin{array}{l}\text { - Structural central nervous system abnormalities, intracranial infections, head } \\
\text { trauma, birth trauma, neonatal insults or hypoxic ischemic encephalopathy, } \\
\text { cerebral palsy, metabolic disorder affecting the CNS, neurobehavioral disorder, } \\
\text { neurodegenerative disorder, and drug-induced neurological manifestation }\end{array}$ \\
\hline $\begin{array}{l}\text { - Normal anthropometric measurements (weight, height and head } \\
\text { circumference) } \\
\text { - Good nutritional status, within normal developmental stage } \\
\text { according to peers }\end{array}$ & $\begin{array}{l}\text { - Patients with poor compliance, low/high doses, or sub-therapeutic range of AEDs } \\
\text { or under polytherapy } \\
\text { - Abnormal anthropometric measurements, feeding difficulties or malnutrition, } \\
\text { with developmental delay or taking antioxidant drugs/vitamins }\end{array}$ \\
\hline
\end{tabular}

\title{
Results
}

Table 1: Age distribution (mean) in groups

\begin{tabular}{|c|c|c|c|c|}
\hline Groups & Number & Age (mo) & Variable & p value \\
\hline \multirow{2}{*}{ LEV } & \multirow{2}{*}{26} & \multirow{2}{*}{113.04} & VPA & .946 \\
\hline & & & Control & .819 \\
\hline \multirow{2}{*}{ VPA } & \multirow{2}{*}{25} & \multirow{2}{*}{117.84} & LEV & .946 \\
\hline & & & Control & .957 \\
\hline Control & 26 & 122.12 & & \\
\hline
\end{tabular}

\section{Liver Function Tests}

Ammonia levels are significantly high in LEV group

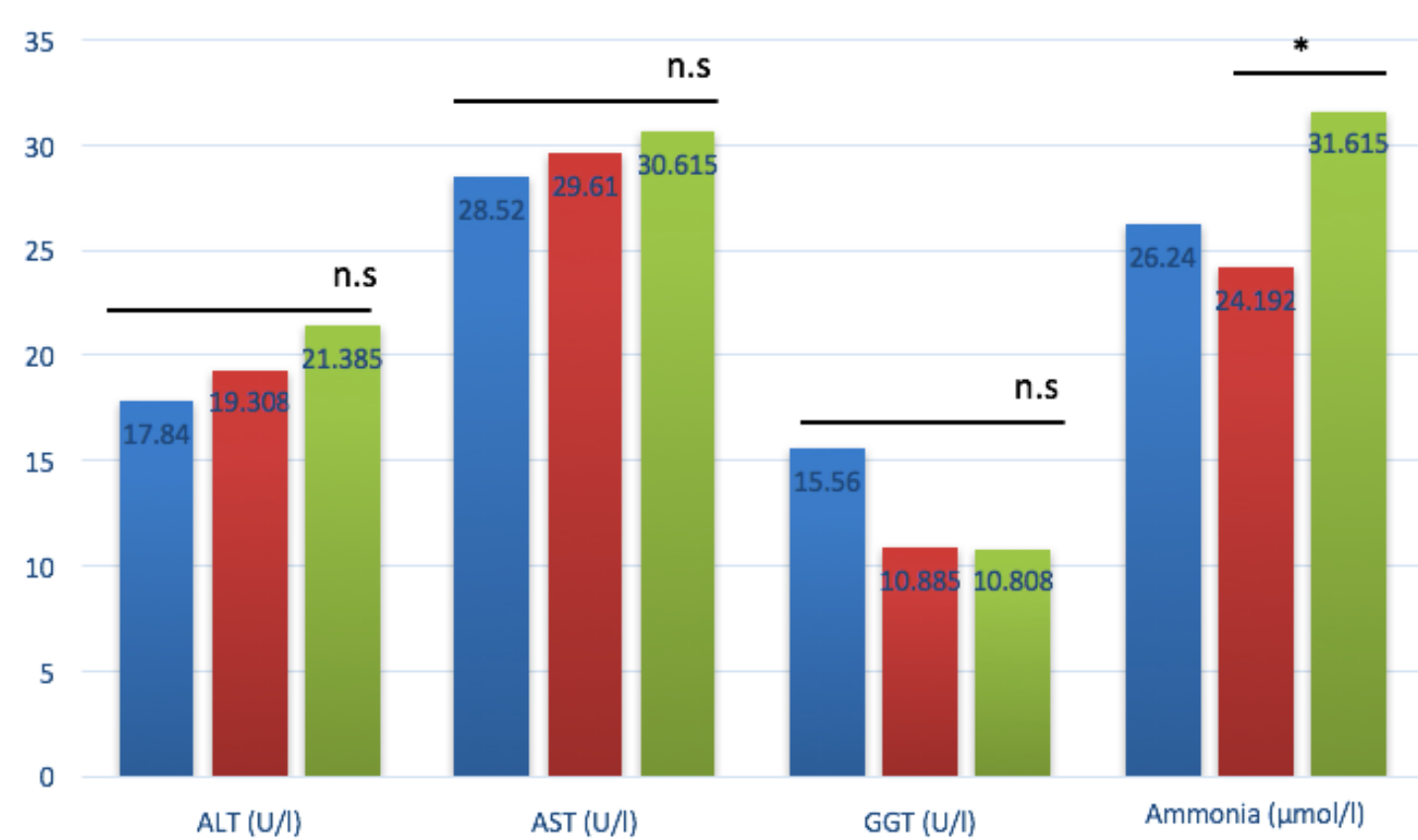

-VPA $=$ Control $=$ LEV

\section{Serum Free Carnitine Levels}$$
\begin{aligned}
& 40 \\
& 35 \\
& 30 \\
& 25 \\
& 20 \\
& 15 \\
& 10 \\
& 5 \\
& 0
\end{aligned}
$$

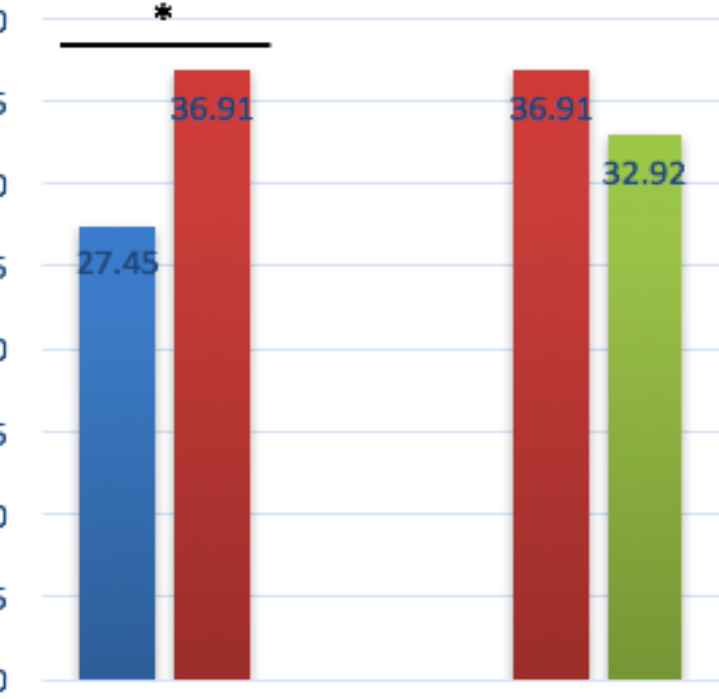

Serum free carnitine is adversely affected due to VPA. Being significantly low, stays in normal range
Table 2: Gender distribution, no significant difference $(p=0,148)$.

\begin{tabular}{|lllll|}
\multirow{2}{*}{ LEV } & \multicolumn{5}{c}{ Gender } & Total \\
& Girls & Boys & \\
\cline { 2 - 5 } VPA & Number & 11 & 15 & 26 \\
\cline { 2 - 5 } & Percentage & $42,3 \%$ & $57,7 \%$ & $100 \%$ \\
\cline { 2 - 5 } & Number & 14 & 11 & 25 \\
\cline { 2 - 5 } & Percentage & $56,0 \%$ & $44,0 \%$ & $100 \%$ \\
\cline { 2 - 5 } & Number & 18 & 8 & 26 \\
\cline { 2 - 5 } & Percentage & $69,2 \%$ & $30,8 \%$ & $100 \%$ \\
\hline
\end{tabular}

\section{Oxidative Stress Parametres}
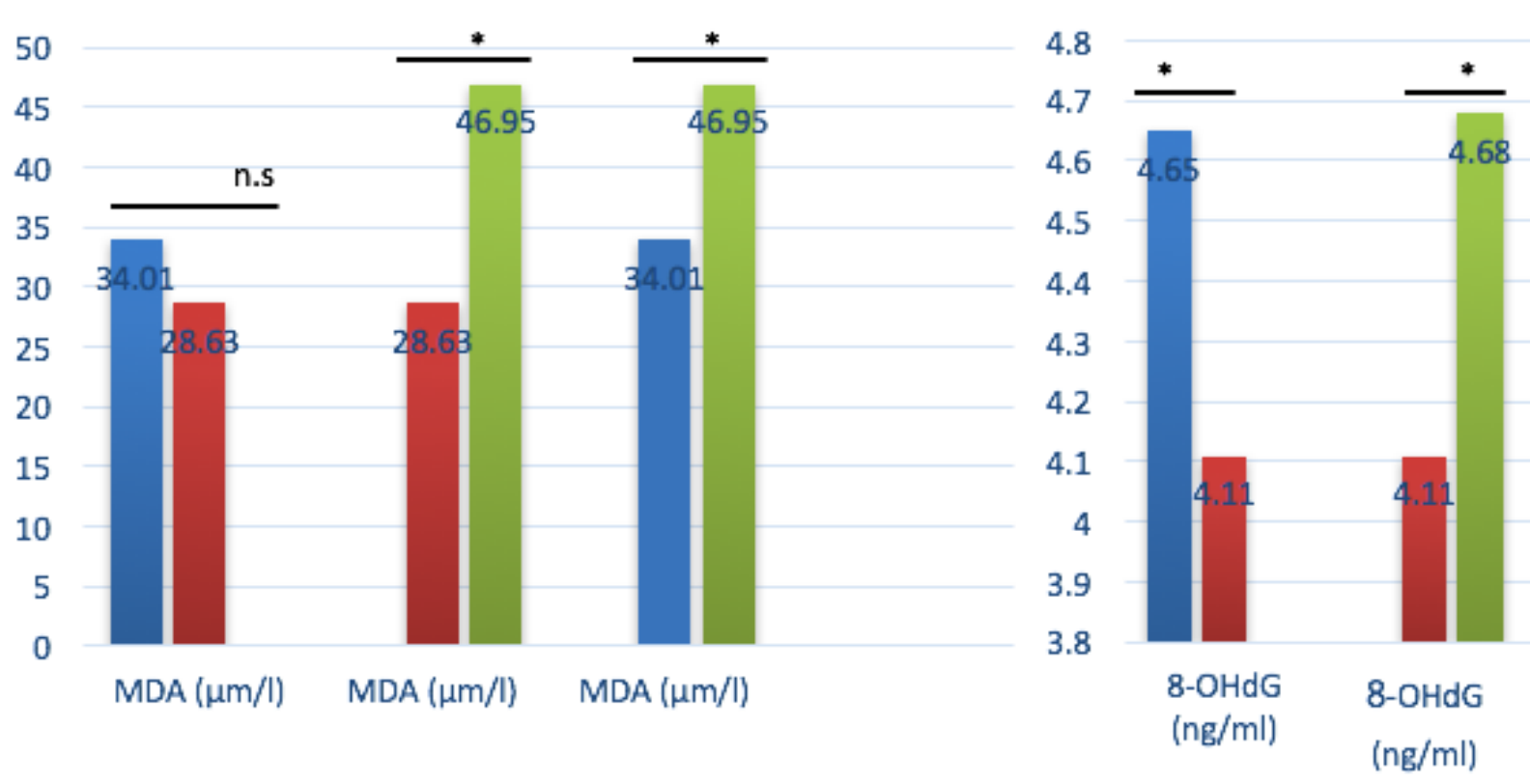

- Oxidative stress parameters are the highest in LEV group

- MDA shows medium correlation with 8-OHdG and low correlation with ammonia in LEV group

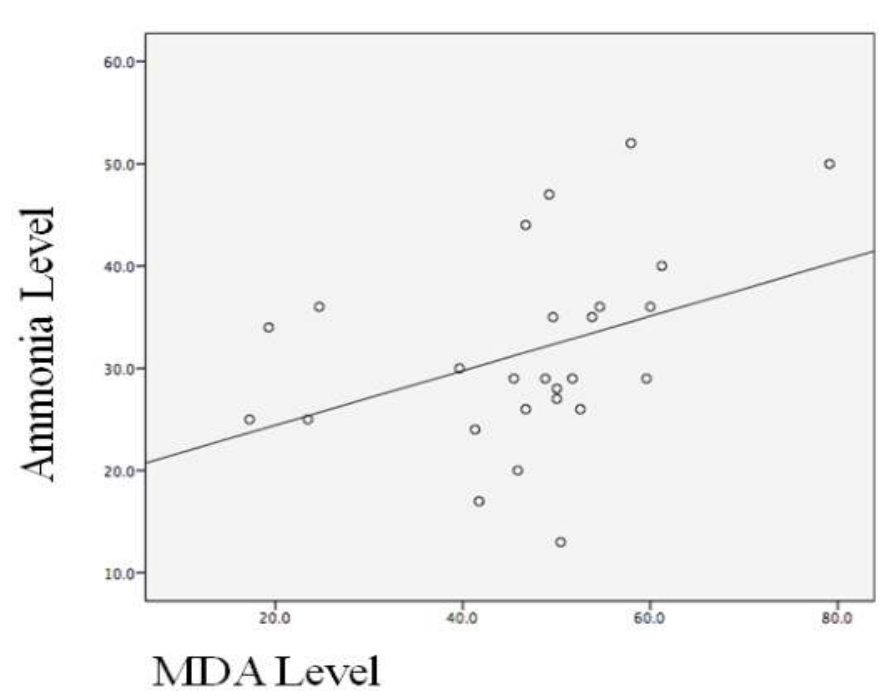

